\title{
Factors Influencing Participation In Professional Developmental Activities Among Nursing Personnel
}

\author{
Rojeena Silwal ${ }^{1}$ and Sarita Panta ${ }^{2}$
}

${ }^{1}$ Nursing Officer, Epidemiology and Disease Control Division, Ministry of Health

${ }^{2}$ College of Nursing, Nepalese Army Institute of Health Sciences, Sanobharyang, Kathmandu, Nepal

\begin{abstract}
Introduction: Professional Developmental Activities (PDA) are the means to update the health care providers with new knowledge and help them to provide quality care and better patient outcomes. This study aims to determine the factors that influence participation in professional development activities among nursing personnel.

Methods: A cross sectional study was conducted among nurses in Tribhuvan University Teaching Hospital, Maharajgung, Kathmandu, Nepal. Simple random sampling technique was used to collect data. Data was collected through self-administered semi-structured questionnaire. The collected data were analysed for descriptive and inferential statistics using SPSS version 20.

Results: Total 124 nurses participated in the study. Most (88.7\%) were working as a staff nurse. Majority $(60.5 \%)$ of nurses had participated in PDA within last 12 months. The most common factors which motivated nurses to participate in PDA were family / spouse support and improve knowledge (98.7\%). The major hindering factors were shortage of staff (97.9\%), and lack of cost (91.8\%). Chi-square and Fisher exact tests were used to test the association of selected variables and PDA participation and significant association was seen between participants designation categorised as staff nurse, senior staff nurse and nursing in charge $(\mathrm{p}<0.008)$ and those who were involved in professional developmental activities.

Conclusions: Based on findings, the study concluded that there are several factors either hindering or motivating related to work, family, financial, personal and career that contributes to nurses participation in PDA.
\end{abstract}

Key words: Factors; Professional developmental activities; Nursing personnel

Correspondence: Rojeena Silwal, Epidemiology and Disease Control Division, Ministry of Health. Email: silwalrojina73@gmail.com

DOI: $10.3126 / \mathrm{mjsbh.v20i1.29061}$

Submitted on: 2020-05-22

Accepted on: 2021-01-10

This work is licensed under creative common license:

http://creativecommons.org/licenses/by-nc-nd/4.0/ (C) MJSBH 2020 


\section{INTRODUCTION}

Professional developmental activities (PDA) are the means to update the health care providers with new knowledge and help them to provide quality care and better patient outcomes. Nurse's participation in PDA is very essential to update them and to have the autonomy to practice evidence based on nursing care which helps for quality patient outcomes. ${ }^{1}$

The various professional organisations like Canadian Nurses Association and American Nurses Association have been consistently insisting their nurses to update their professional knowledge, skills and judgments to provide competent and safe care. ${ }^{2,3}$ Most of the developed countries like UK, US and Australia have license renewal examination system and mandatory continuing professional developmental activities existing which makes the nurse self-motivated towards the improvement of their competencies and result in better satisfaction. ${ }^{1}$ Basic nursing education alone cannot effectively meet the challenging and complex demands of the expanding range of health care. There are many barriers like lack of funds, lack of time, lack of professional supports, lack of motivation, lack of study time, lack of access to relevant courses, heavy workload in organisation, family responsibilities and child care and difficult to travel. $^{4}$

Nursing itself is a challenging profession and nurses continuously need to update their knowledge and skills to provide competent care for which they need to participate in PDA. There are various factors that affect the nursing participation in which need to be considered before planning the PDA for nurses. Therefore, this study was conducted to identify the motivating and hindering factors that influence participation in PDA among nursing personnel. Findings of this study might be helpful to health and nursing institutions as well as professional organisations in facilitating professional development activities to promote the professional status of nursing in the country and to improve the quality of nursing care through evidence based practice.

\section{METHODS}

Study adopted a cross-sectional descriptive survey design. Registered nurses were surveyed from different wards of Tribhuvan University Teaching
Hospital, Maharajgung, Kathmandu, Nepal. They were randomly selected by using table of random numbers. All the nurses who had at least six months working experience and who were willing to participate were included in the study whereas those who were not interested and were on leave were excluded from the study. Data was collected through semi-structured questionnaire from June 10 to June 28, 2019. The questionnaire consisted of three parts where Part I covered the sociodemographic information, Part II was related to PDA and part III consisted of motivating and hindering factors on participation in professional development activities which had a total 39 items, with 19 items as motivating factors and 20 items as hindering factors. The questionnaire comprised the subareas of factors such as work related, family related, financial and personal and career factors. Respondents were given "yes" or "no" options for each factor. Content validity and consistency of the tool was maintained through the use of pretested questionnaire among 12 participants i.e. $10 \%$ of sample size at Grande International hospital. Ethical approval was taken from Institutional Ethical Review Committee of Nepalese Army Institute of Health Sciences. Permission was taken from Chief of Clinical Administration of concerned tertiary care referral centre and informed written consent was obtained from each respondent before data collection. Every precaution was taken to safeguard the right of the respondents.

Data analysis was done using Statistical Package for Social Science (SPSS version 20). Data was analysed and described using frequency, percentage, mean and standard deviation. Inferential statistics i.e. Chi square and Fisher exact test were used to analyse the associations and $\mathrm{P}$ value $<0.05$ shows significant association.

\section{RESULTS}

Total 124 registered nurses participated in the study. The sample showed that mean age of the participants was 28.63 years $(\mathrm{SD} \pm 6.906)$; half were married; $62 \%$ from single family, more than one fourth $(29.8 \%)$ of the nurses are currently working in surgical ward, majority $(63.7 \%)$ of nurses had less than five years of clinical experience. Highest proportion $(41.1 \%)$ of the participant held PBBN / BNS (Post Basic Bachelor in Nursing / Bachelor in Nursing Science) level of 
Table 1. Respondent's Socio-demographic Information

\begin{tabular}{|c|c|c|}
\hline Variables & Frequency & Percentage \\
\hline \multicolumn{3}{|l|}{ Age in years } \\
\hline $20-30$ & 31 & 25.0 \\
\hline $31-40$ & 39 & 31.5 \\
\hline $41-50$ & 24 & 19.4 \\
\hline $50+$ & 30 & 24.2 \\
\hline \multicolumn{3}{|l|}{$\begin{array}{l}\text { Mean age } \pm S D=28.63 \pm \\
6.906\end{array}$} \\
\hline \multicolumn{3}{|l|}{ Marital status } \\
\hline Married & 62 & 50.0 \\
\hline Unmarried & 61 & 49.2 \\
\hline Widow & 1 & 0.8 \\
\hline \multicolumn{3}{|l|}{ Family type } \\
\hline Single & 78 & 62.9 \\
\hline Joint & 42 & 33.9 \\
\hline Extended & 4 & 3.2 \\
\hline \multicolumn{3}{|l|}{ Work experience in years } \\
\hline$<5$ & 56 & 45.2 \\
\hline $5-10$ & 32 & 25.8 \\
\hline$>10$ & 36 & 29.0 \\
\hline \multicolumn{3}{|l|}{$\begin{array}{l}\text { Mean work experience } \pm \\
\mathrm{SD}=6.41 \pm 7.007\end{array}$} \\
\hline \multicolumn{3}{|l|}{$\begin{array}{l}\text { Highest level of nursing } \\
\text { education }\end{array}$} \\
\hline PCL nursing & 27 & 21.8 \\
\hline $\mathrm{PBBN} / \mathrm{BNS}$ & 51 & 41.1 \\
\hline B. Sc. Nursing & 42 & 33.9 \\
\hline $\mathrm{MN}$ & 4 & 3.2 \\
\hline \multicolumn{3}{|l|}{ Designation } \\
\hline Staff Nurse & 110 & 88.7 \\
\hline Senior Staff Nurse & 5 & 4.0 \\
\hline Nursing Incharge & 9 & 7.3 \\
\hline
\end{tabular}

nursing education and most (88.7\%) nurses worked as a staff nurse as shown in Table 1.

The majority (60.5\%) of respondents had participated in PDA within last 12 months, 53.3\% had participated in PDA for one to three times. Highest proportion (44.0\%) of respondents had participated in in-service education, majority (61.3\%) of respondents mentioned the criterion of PDA participation was experience and most $(77.3 \%)$ respondents had mentioned that their ward in-charge made decision of participation in PDA. All respondents mentioned that PDA they had participated was useful in their current workplace.

As shown in Table 2, among 75 nurses who had participated in PDA within last 12 months, most common factors which motivated nurses to participate in PDA were family / spouse support (98.7\%), improve knowledge (98.7\%), keep oneself up to date $(98.7 \%)$, enhance personal confidence (98.7\%), become aware of technological advancement (98.7\%), develop proficiency necessary to meet patient need $(98.7 \%)$.

Table 3 shows that among 49 nurses who hadn't participated in PDA within last 12 months, the most common hindering factors were shortage of staff $(97.9 \%)$, lack of opportunities for promotion (97.9\%), lack of cooperation from management (93.8\%), too much work load $(91.8 \%)$, lack of cost / funds (91.8\%), unnecessary expenditure (89.7\%), responsibilities at home (87.7\%), and no off from duty schedule (87.7\%).

Table 4 reveals significant association between designations of nurses with participation in PDA ( $p$ value 0.008 ) other than that there is no any significant association between other selected variables and participation in PDA.

\section{DISCUSSION}

Nurses' participation in PDA is very essential in order to enable them to have up-to-date knowledge and skills to maintain and improve the quality of patient care. This study investigated various factors which may motivate the nurses to participate in these activities and hindering factors which may prevent nurses in attending PDA. The present study reveals that only $60.5 \%$ of nurses had participated in PDA within last 12 months which is similar to the findings of a cross sectional descriptive study done in Malaysia in which $71 \%$ nurses had attended continuing professional education in last 12 months. ${ }^{5}$ This finding was in contrast with a descriptive study done in Saudi Arabia where only $18.2 \%$ had enrolled in PDA. The disparity in findings may be due to different study setting, smaller sample size and study conducted in only one hospital. ${ }^{6}$

In the current study, the most common factors which motivated nurses to participate in PDA were 
Table 2. Motivating Factors that Influences Nurses Participation in PDA (N=75)

\begin{tabular}{|c|c|c|c|c|}
\hline \multirow[t]{2}{*}{ Motivating factors } & \multicolumn{2}{|l|}{ Yes } & \multicolumn{2}{|c|}{ No } \\
\hline & Frequency & Percentage & Frequency & Percentage \\
\hline \multicolumn{5}{|l|}{ Work related factors } \\
\hline Compulsory attendance requirement in PDA & 67 & 89.3 & 8 & 10.7 \\
\hline Break from routine work schedule & 68 & 90.7 & 7 & 9.3 \\
\hline Class planned after duty timings & 42 & 56.0 & 33 & 44.0 \\
\hline Offered by qualified resource person & 73 & 97.3 & 2 & 2.7 \\
\hline \multicolumn{5}{|l|}{ Family related factors } \\
\hline Family / spouse support & 74 & 98.7 & 1 & 1.3 \\
\hline Less family responsibilities & 49 & 65.3 & 26 & 34.7 \\
\hline \multicolumn{5}{|l|}{ Financial factors } \\
\hline Programs offered free of cost & 71 & 94.7 & 4 & 5.3 \\
\hline Expenses which is refundable & 58 & 77.3 & 17 & 22.7 \\
\hline Less travelling expenses & 57 & 76.0 & 18 & 24.0 \\
\hline \multicolumn{5}{|l|}{ Personal and career factors } \\
\hline Create friendship with people of various professions & 72 & 96.0 & 3 & 4.0 \\
\hline Have some good time with friends & 70 & 93.3 & 5 & 6.7 \\
\hline Improve knowledge & 74 & 98.7 & 1 & 1.3 \\
\hline Keep oneself upto date & 74 & 98.7 & 1 & 1.3 \\
\hline Entrance to other college or job & 60 & 80.0 & 15 & 20.0 \\
\hline Develop proficiency necessary to meet patient need & 74 & 98.7 & 1 & 1.3 \\
\hline Develop leadership capabilities & 72 & 96.0 & 3 & 4.0 \\
\hline Enhance personal confidence & 74 & 98.7 & 1 & 1.3 \\
\hline Become aware of technological advancement & 74 & 98.7 & 1 & 1.3 \\
\hline For sake of promotion & 59 & 78.7 & 16 & 21.3 \\
\hline
\end{tabular}

family / spouse support, aim to improve knowledge, keep oneself up to date, enhance personal confidence and become aware of technological advancement which was present in almost all participants. The present study is in consistent with a cross-sectional descriptive study done in India in which the most common factors which motivated nurses' to participate in PDA were improvement of knowledge (96.6\%), fine-tuning of nursing skills (95.3\%), technological advancement (95.3\%), and keeping oneself up-to-date (86.6\%). ${ }^{1}$ Similarly a study done in Nigeria showed that major motivating factors identified by the participants to undertake in Continuing Formal Education (CFE) were to gain knowledge and skills (83\%), developing leadership capabilities (64\%) and to improve confidence (96\%) which support the findings of the present study. ${ }^{7}$
This study found that the most common hindering factors were shortage of staffs, too much work load, no off from duty schedule and responsibilities at home. The findings are supported by a crosssectional descriptive study done in India where among 320 nurses, the most common factors which hindered nurses to participate in PDA were excessive indirect cost and lack of relieving staff. More than half of respondents had responsibilities at home $(55.9 \%)$, could not afford the cost of registration $(50.3 \%)$ and no off from duty schedule (45.3\%). ${ }^{1}$ Similarly a descriptive cross-sectional study done in Western Kenya among 235 nurses revealed staff shortage $(85.8 \%)$, lack of time due to heavy work load $(77.2 \%)$, lack of finance $(59.1 \%)$, family commitment (28.9\%) which is consistent with the findings of present study. ${ }^{8}$ 
Table 3. Hindering Factors that Influences Nurses Participation in PDA $(\mathrm{N}=49)$

\begin{tabular}{|c|c|c|c|c|}
\hline \multirow[t]{2}{*}{ Hindering Factors } & \multicolumn{2}{|l|}{ Yes } & \multicolumn{2}{|c|}{ No } \\
\hline & Frequency & Percentage & Frequency & Percentage \\
\hline \multicolumn{5}{|l|}{ Work related factors } \\
\hline Too much workload & 45 & 91.8 & 4 & 8.2 \\
\hline Shortage of staff & 48 & 97.9 & 1 & 2.1 \\
\hline Lack of cooperation from management & 46 & 93.8 & 3 & 6.1 \\
\hline No off time from duty schedule & 43 & 87.7 & 6 & 12.3 \\
\hline Lack of role model in work place & 42 & 85.7 & 7 & 14.3 \\
\hline Lack of opportunities for promotion & 48 & 97.9 & 1 & 2.1 \\
\hline Lack of opportunities to utilise new skills in work place & 42 & 85.7 & 7 & 14.3 \\
\hline \multicolumn{5}{|l|}{ Family related factors } \\
\hline Difficult to leave children at home & 37 & 75.5 & 12 & 24.5 \\
\hline Responsibilities at home & 43 & 87.7 & 6 & 12.3 \\
\hline Prefer to spend time with family & 38 & 77.5 & 11 & 22.5 \\
\hline \multicolumn{5}{|l|}{ Financial factors } \\
\hline Lack of cost/ fund & 45 & 91.8 & 4 & 8.2 \\
\hline Unnecessary expenditure & 44 & 89.7 & 5 & 10.3 \\
\hline Difficult to travel & 42 & 85.7 & 7 & 14.2 \\
\hline \multicolumn{5}{|l|}{ Personal and career factors } \\
\hline Difficulty in language & 28 & 57.2 & 21 & 42.8 \\
\hline Topics which are difficult to understand & 29 & 59.1 & 20 & 40.9 \\
\hline Lack of satisfaction and motivation in learning & 41 & 83.7 & 8 & 16.3 \\
\hline Previous experience was disappointing & 32 & 65.4 & 17 & 34.6 \\
\hline Inappropriate to clinical practice need & 35 & 71.5 & 14 & 28.5 \\
\hline Lack of opportunities for personal development & 37 & 75.5 & 12 & 24.5 \\
\hline
\end{tabular}

Table 4. Association of Selected Socio-demographic Variables with Participation in PDA

\begin{tabular}{|c|c|c|c|c|c|c|}
\hline \multirow[t]{3}{*}{ Variables } & \multicolumn{4}{|c|}{ Participation in PDA } & \multirow[t]{3}{*}{$\mathbf{X}^{2}$} & \multirow[t]{3}{*}{ P-value } \\
\hline & \multicolumn{2}{|c|}{ Yes } & \multicolumn{2}{|c|}{ No } & & \\
\hline & No. & $\%$ & No. & $\%$ & & \\
\hline \multicolumn{7}{|l|}{ Age of the respondents } \\
\hline$\leq 40$ & 38 & 54.3 & 32 & 45.7 & 2.584 & 0.108 \\
\hline$>40$ & 37 & 68.5 & 17 & 31.5 & & \\
\hline \multicolumn{7}{|l|}{ Marital status } \\
\hline Married & 35 & 56.4 & 27 & 43.6 & 0.718 & $0.463 \#$ \\
\hline Single (unmarried, widow) & 40 & 64.5 & 22 & 35.5 & & \\
\hline \multicolumn{7}{|l|}{ Family type } \\
\hline Single & 45 & 57.6 & 33 & 42.4 & 0.686 & $0.451 \#$ \\
\hline joint and extended & 30 & 65.2 & 16 & 34.8 & & \\
\hline \multicolumn{7}{|l|}{ work experience } \\
\hline$<10$ & 35 & 53.8 & 30 & 46.2 & 2.518 & 0.113 \\
\hline$>10$ & 40 & 67.7 & 19 & 32.3 & & \\
\hline \multicolumn{7}{|l|}{ Designation } \\
\hline Staff nurse & 62 & 56.4 & 48 & 43.6 & 6.920 & $0.008 \# * *$ \\
\hline Others( Senior staff nurse \&incharge) & 13 & 92.8 & 1 & 7.2 & & \\
\hline
\end{tabular}

Note: ** significant, \# Fisher exact test 
In the current study, significant association was seen only in designation of nurses as categories in position of nurse and participation in PDA $(\mathrm{p}<$ 0.008 ) with senior nurses having more opportunity to attend such activities. The findings are supported by a cross-sectional descriptive study conducted in Iran shows significant association with nurse's position $(\mathrm{p}<0.047){ }^{9}$

\section{CONCLUSIONS}

In this study majority of respondents had participated in PDA although still not sufficient. Overall, nurses participation in PDA was influenced by various factors either motivating or hindering related to work, family, financial and personal and career factors. Therefore the administrators and nurse educator need to motivate the nurses in attending PDA by utilising the motivating factors and find means to overcome the hindering factors to improve the overall quality of nursing care.

\section{ACKNOWLEDGEMENT}

The researcher is highly indebted to Chief of Clinical Administration Mr. Ram Bikram Adhikari of Tribhuvan University Teaching Hospital for granting permission to collect data in different wards and all the respondents who gave their time to collect data for this research study. We also acknowledge the Institutional Ethical Review Committee of the Nepalese Army Institute of Health Sciences for providing ethical clearance for the study.

To cite this article: Silwal R, Panta S. Factors Influencing Participation In Professional Developmental Activities Among Nursing Personnel. MJSBH. 2021;20(1):24-9.

Conflict of Interest: None declared

\section{REFERENCES}

1. Sharon S, Latha T, D’Souza PJ. Factors influencing nurses' participation in professional developmental activities. IJHSR. 2015;5(9):384-8

2. Canadian Nurses Association. Policy Statement (1998) Educational Support for Competent Nursing Practice. CNA, Ottawa.

3. American Nurses' Association. Scope and standards of practice for nursing professional development. American Nurses Association; 2000.

4. Schweitzer DJ, Krassa TJ. Deterrents to nurses' participation in continuing professional development: An integrative literature review. JCEN. 2010; 41(10):441-7. DOI:10.3928/00220124-20100601-05

5. Chong MC, Sellick K, Francis K, Abdullah KL. What influences Malaysian nurses to participate in continuing professional education activities? Asian Nursing Research. 2011;5(1):38-47. DOI: 10.1016/S1976-1317(11)60012-1

6. Aboshaiqah AE, Qasim A, Abualwafa N. Barriers for Continuing Professional Development among Nurses in Saudi Arabia. Middle East J Nurs. 2012;101(344):1-6.

7. Adamu A, Adeleke IT, Aliyu D, Mahmud T. Perspectives of continuing formal education among nurses in selected secondary healthcare facilities in Northern Nigeria. AJHR. 2015;3(1):68-73. DOI:10.11648/j.ajhr.s.2015030101.20

8. Gitonga L, Muriuki NS. Perspectives of continuing professional development (CPD) for Kenyan midwives. OJCD. 2014;2014. DOI:10.4236/ojcd.2014.42015

9. Sajjadnia Z, Sadeghi A, Kavosi Z, Zamani M, Ravangard R. Factors affecting the nurses' motivation for participating in the in-service training courses: a case study. JHMI. 2015;2(1); 21-6. 